\title{
Soft bandaging versus casting in the treatment of torus fracture of distal radius in children; a prospective randomized study
}

\author{
Prakash Bahadur Thapa, Rudra Prasad Marasini, Trithendra Khadka, Shrawan Kumar Thapa, \\ Nabeesman Singh Pradhan, Shreekrishna Giri \\ Department of orthopaedics and trauma, National Academy of Medical Sciences, Kathmandu Nepal.
}

\author{
Correspondence \\ Dr. Rudra Prasad Marasini \\ Dept. of Orthopedics, \\ National Academy of Medical \\ Sciences \\ Email: \\ drmarasinirp@gmail.com
}

DOI: http://dx.doi.org/10.3126/ jcmsn.v11i4.14317

\begin{abstract}
Background \& Objectives: Various methods of immobilization have been recommended for the treatment of torus fracture of distal radius in children. The purpose of this study is to determine if soft bandage is as effective and safe as below elbow circumferential casts in the treatment of torus fracture of the distal radius in the children. Materials \& Methods: Children from 4 to 14 years of age, who presented to emergency and outpatient department of orthopaedics and trauma at National Academy of Medical Sciences with an isolated torus fracture of distal radius, were randomized and treated with either soft bandage or below-elbow plaster cast by the same investigators. Patients with associated neurovascular injuries, bilateral torus fractures, concomitant physeal injuries and associated musculoskeletal injuries were excluded. The patients were followed up at weekly interval for 4 weeks and analyzed with VAS, ROM and outcome questionnaire and data were analyzed by using SPSS 18. Results: Among the 114 patients analyzed, 57 patients were kept in soft bandage group and 57 in below-elbow cast group. The mean age in soft bandage group was 8.29 year and the mean age in below-elbow cast group was 8.55 years. There was no significant difference between the two groups with regard to patient demographics, initial fracture characteristics and mechanism of injury. Conclusion: Treatment of distal radius torus fracture with soft bandage is a cost-effective and safe in the children below 14 years of age. These minor fractures are stable and not subject to the risks of late displacement which can be very effectively treated symptomatically to provide pain relief by using soft bandage only and educating the parents about the nature of this paediatrics fracture.

Key words: Buckle; Casting; Distal radius; Soft bandage; Torus fracture.
\end{abstract}

Citation: Thapa PB, Marasini RP, Khadka T, Thapa SK, Pradhan NS, Giri S. Soft bandaging versus casting in the treatment of torus fracture of distal radius in children; a prospective randomized study. JCMS Nepal. 2015;11(4):3-8.

\section{INTRODUCTION}

Fractures of the distal radius in children are very common and often results due to fall on an out stretched hand. ${ }^{1}$ Torus or buckle fracture is a compression failure of bone in which the cortex bulges due to longitudinally applied compressive force and normally occurs in the transitional zone between the metaphysis and diaphysis. They are common in the distal radius and show little or no tendency to displace. ${ }^{2}$ Torus fracture produces the characteristic bulge or "buckle" on radiographs and these are inherently stable. They clinically exhibit minimal symptoms, usually only local tenderness, and little apparent deformity. ${ }^{3,4}$ Treatment is, therefore, symptomatic only, providing pain relief through splintage for the patient and re-assurance for the parents. ${ }^{5,6,7}$ This is a prospective randomized study comparing the functional outcome of treatment of torus fracture distal radius with soft bandage and plaster cast aiming to show that buckle fractures of the distal radius may be safely and effectively treated in a soft bandage without adverse effects and with a high degree of patient satisfaction. The benefits of soft bandage application are easier application, greater patient comfort, less pain, less number of clinic visit, less time loss from school and low cost. ${ }^{1,4,6-8}$ As for the available literatures, there has not been any study performed comparing the outcome of soft bandage and plaster cast for immobilization of torus fracture 
of distal radius in children in Nepal till now. The purpose of this study is to determine the effectiveness of using a soft bandage over plaster cast in the treatment of wrist torus fractures and to radio-graphically verify the inherent stability of torus fractures in the face of minimalistic immobilization.

\section{MATERIALS AND METHODS}

This is a clinical prospective randomized study comparing the outcome of torus fracture of distal radius treated by soft bandage and plaster cast, conducted in the department of Orthopaedics and trauma at National Academy of Medical Sciences Kathmandu Nepal, during the period of 3 years (August 2012 to April 2015). Total 114 patients (57 in each group) were included in the study. Every alternate patient visiting the emergency and outpatient department with torus fracture of distal radius were allocated into two different groups with even number in soft bandage group and odd number in below elbow cast group. Children with unilateral isolated distal radius torus fracture within the age of $4-14$ years were only included in the study after an informed consent from the parents (Figure 1). Children with bilateral torus fractures, associated physeal injuries, neurovascular injuries and other musculoskeletal injuries were excluded from the study. Treatment randomization was done based on the patient enrolment, if the entry number was odd, $\mathrm{B} \backslash \mathrm{E}$ plaster cast was applied and if entry number was even then soft bandage was applied.

Plaster cast: For plaster cast group, cotton padding was applied from below elbow to metacarpophalangeal joints. Circumferential belowelbow cast was applied extending from five centimeter below- elbow to the metacarpal heads. The forearm was kept in supination and the wrist in neutral position in the cast. Patients treated in a $B \backslash E$ plaster cast were seen next day, at 1 week and next seen at 4 weeks. The purpose of calling next day was to evaluate if any complications related to cast has occurred. At last visit (4wks), the cast was removed and measurements of their range of movement were made and recorded (Figure 2).

Soft bandage group: Patients allocated to be treated with soft bandage had a layer of orthopedics wool applied and this was covered with a layer of ordinary commercial cotton crepe bandage, which was held with the tape. All patients were seen at 1 week. Those treated in a soft bandage had it removed; range of movement was measured in the clinic using a goniometer and the results were recorded. The bandage was then reapplied. For the purposes of the trial all bandage patients were seen at weekly intervals up to a total of 4 weeks. Measurements of their range of movement were recorded at each week. Parents were encouraged to report any adverse incidents immediately (Figure 3).

Parents of all patients were asked to complete the questionnaire at the child's final appointment and their responses were analyzed. After completion of the questionnaire, patients were discharged. Statistical analysis was performed by using statistical programme SPSS 18. Comparison of the qualitative variables was done by " $t$ " test. Values of $\mathrm{p}<0.05$ were considered significant with confidence level of $95 \%$ throughout the study.

\section{RESULT}

Out of 120 patients included in the study 60 soft bandages and 60 below-elbow casts were applied. Three cases from each group were lost during follow up, so that only 57 children from soft bandage group and 57 patients from $\mathrm{B} \backslash \mathrm{E}$ cast group were included in the final analysis. The minimum age of the patient was 5 years and the maximum age of the patient was 14 years with mean age of 8.42 years. The mean age in soft bandage group was 8.29 year and the mean age in below-elbow cast group was 8.55 years. Out of 114 patients, $73.68 \%$ (84) were male and $26.31 \%$ (30) were female. There were 44 males and 13 females in soft bandage group and 40 males and 17 females in $\mathrm{B} \backslash \mathrm{E}$ cast group. Mechanism of injury was predominantly fall from height $82(71.92 \%)$ fallowed by sports injury $28(24.56 \%)$ and RTA $4(3.50 \%)$. Out of 114 children enrolled in the study, $104(91.2 \%)$ were right handed and $10(8.8 \%)$ were left handed though $78(68.4 \%)$ children had injured the left hand and only $36(31.6 \%)$ had right hand injury.

The following factors (Average cost of treatment, Number of loss of school days, ROM of wrist at 4 weeks, Comfortability, Pain, Bandage removal during treatment, Wrist movement, Convenience and Parent's concerns) were analysed and compared between the two groups.

Average cost of treatment: The mean cost of applying soft bandage was NRs. 301.25 compared to the cost of NRs. 541.92 for applying a belowelbow cast. There was a statistically significant decrease in cost by application of soft bandage as compared to below-elbow cast $(p=0.000)$. 


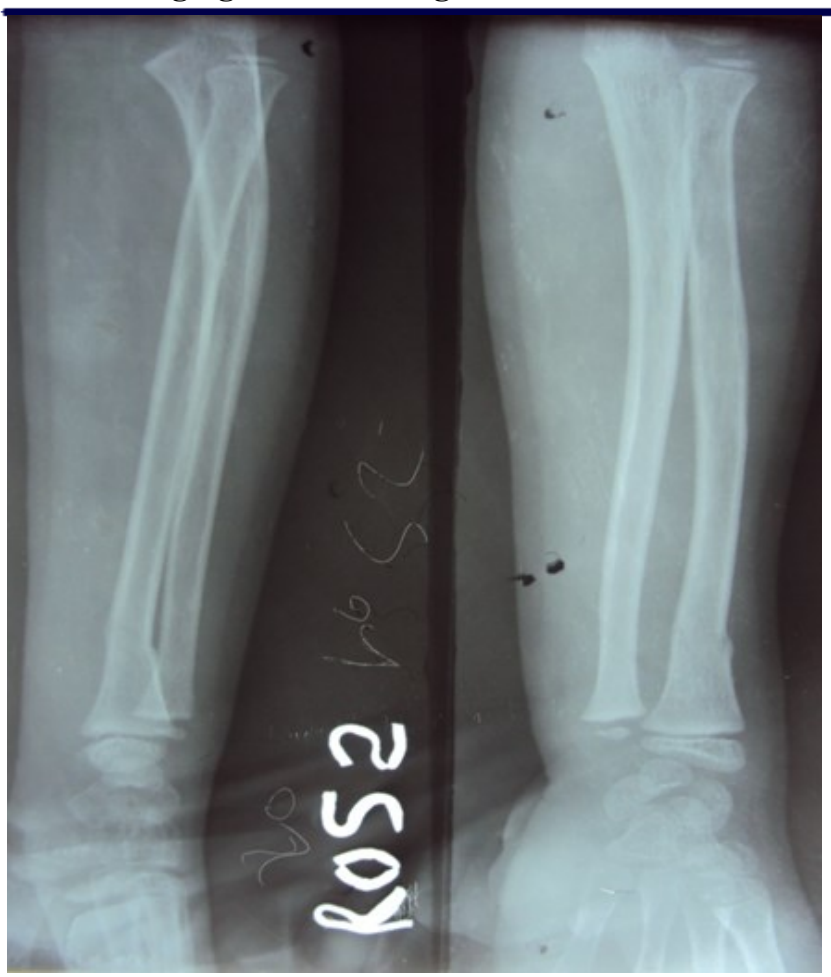

Figure 1. Radiograph showing the antero-posterior and lateral view of torus fracture of distal radius.

Loss of school days: Out of the 114 children enrolled in the study, the average loss of school in soft bandage group was 1.6 days whereas children in $\mathrm{B} \backslash \mathrm{E}$ cast group was 2.8 days.

Range of motion of wrist at 4 weeks: In soft bandage group, the mean dorsiflexion of wrist after removal of bandage at 4 wks was $69.36^{\circ}$ compared to the mean dorsiflexion of wrist in $\mathrm{B} \backslash \mathrm{E}$ cast group which was $64.07^{\circ}$. This was statistically significant $(p=0.00)$. Similarly mean palmar flexion of wrist at 4 wks after removal of bandage in soft bandage group was $78.36^{\circ}$ while in $\mathrm{B} \backslash \mathrm{E}$ cast it was $69.48^{\circ}$. This was also statistically significant. $(p=0.00)$. In soft bandage group, the mean supination of wrist after removal of bandage at 4 wks was $78.50^{\circ}$ compared to the mean supination of wrist in $B \backslash E$ cast group which was $73.66^{\circ}$. This was statistically significant $(p=0.00)$. Similarly mean pronation of wrist at 4 wks after removal of bandage in soft bandage group was $68.50^{\circ}$ while in $\mathrm{B} \backslash \mathrm{E}$ cast it was $64.17^{\circ}$. This was also statistically significant. $(\mathrm{p}=$ $0.00)$.

Comfortability: Patients were asked how comfortable they found the treatment in either the soft bandage or the $\mathrm{B} \backslash \mathrm{E}$ plaster cast group. Twenty eight $(49.12 \%)$ patients in the soft bandage group were very comfortable, $26 \quad(45.61 \%)$ were comfortable and 3 patient $(5.26 \%)$ was undecided and neither of the patients was uncomfortable.
Whereas in the $\mathrm{B} \backslash \mathrm{E}$ cast group, neither of the patients was very comfortable but $28(49.12 \%)$ patients were comfortable, 17 (29.86\%) patients were undecided and $12(21.05 \%)$ patients were uncomfortable (Figure 4).

Pain: Patients were also asked about pain in either the soft bandage group or the $\mathrm{B} \backslash \mathrm{E}$ plaster cast. For those treated in a soft bandage group, $15.78 \%$ (9) had pain and $84.21 \%$ (48) did not have pain in a bandage. For those treated in a $\mathrm{B} \backslash \mathrm{E}$ plaster cast, 38.59\% (22) had pain and 61.40\% (35) did not have pain in a plaster cast. All patients were asked about the duration of the pain they experienced. For patients who had pain in the bandage, most of them had pain for 2 days. For those who had pain in the plaster cast, most of them had pain for 4 to 5 days. Severity of pain was analysed by using VAS score.

Movements of wrist: Patients were asked whether they had moved their wrist in the bandage. Forty $(70.17 \%)$ patients in the soft bandage group agreed that they used and moved their wrist and 17 $(29.82 \%)$ patients didn't. No patients treated in the $\mathrm{B} \backslash \mathrm{E}$ plaster cast removed their cast or were able to move their wrist until the fourth week, upon removal.

Bandage removal: Patients treated in a soft bandage group were asked whether they removed the bandage during the treatment. Twenty-eight $(49.12 \%)$ patients said that they removed the bandage and re-applied at home while in treatment whereas $29(50.87 \%)$ patients did not remove. It was not possible to remove cast in $\mathrm{B} \backslash \mathrm{E}$ group.

Convenience: Patients were asked whether they found treatment in either the bandage or the plaster cast convenient. In soft bandage group, 52 $(91.22 \%)$ patients were convenient regarding the form of treatment and $5(8.77 \%)$ were not whereas $36(63.15 \%)$ patients were convenient and 21 (36.84\%) patients were not convenient in $\mathrm{B} \backslash \mathrm{E}$ cast group.

Parent's concerns: Parents were asked whether they felt worried entering the trial. For those treated in soft bandage $22(38.59 \%)$ responded that they had been worried and $35(61.50 \%)$ had not. For those treated in plaster cast all of them (57) responded that they had not been worried (Table 2).

\section{DISCUSSION}

The buckle (torus) fracture is a fracture in which the cortex bulges due to longitudinally applied compressive force. It is a fracture in the transition zone between metaphysic and diaphysis of long 
bone1. Recent publications agreed that the buckle fracture is a stable injury with little or no chance of displacement. These fractures require supportive treatment, but the duration of such treatment varies with the institution. The type of supportive treatment also varies, but all these studies have concentrated on rigid support 1, 2.There is still a variation in the treatment of buckle fracture of the distal radius in children. Studies have shown that a torus fracture is stable and follow-up radiographs are not required because the tension side of the cortex remains intact and should thus not deform2, 3 , 4. Several recent studies have highlighted the fact that buckle fractures of the distal radius in children are stable injuries that do not require prolonged treatment in the fracture clinic. The buckle or torus fracture may be treated in plaster cast, "Futuratype" wrist splints or moldable removable polymer casts. All these studies have highlighted the fact that the accepted treatment of such fractures in a plaster cast for 2 to 4 weeks is unnecessary; however, each has concentrated on replacing the plaster cast with some other form of rigid immobilization 2-6, 7. This study aimed to show that buckle fractures of the distal radius may be safely and effectively treated in a soft bandage without adverse effects and with a high degree of patient satisfaction7- 9. The soft bandage and $B \backslash E$ cast groups were similar with respect to age, gender, fracture types, side distribution, and mechanism of injury, hand dominance and time of presentation which indicated that randomization had been effective

In this study, the age of the patient ranged from five years to 14 years. The minimum age for using $B \backslash E$ cast was set at five years because below this age, there is high chance of cast slippage pertaining to small size of forearm. The mean age of patients in soft bandage group was 8.29 years and $\mathrm{B} \backslash \mathrm{E}$ cast group was 8.55 years. In a randomized prospective study by Simon West et al 2, the minimum age of patient was five years. The mean age in soft bandage group was 8.25 years and the mean age in $\mathrm{B} \backslash \mathrm{E}$ cast group was 8.90 years. The sex distribution in this study very similar to the study of Khan KS et al. in which $79.56 \%$ (68 out of 117) of patients were male and $20.44 \%$ (49 out of 117 ) of patients were female with the male: female ratio of 1.39:13. Among the 114 children enrolled in the study, 104 (91.2\%) were right handed and $10(8.8 \%)$ were left handed though $78(68.4 \%)$ children had injured the left hand and only $36(31.6 \%)$ had injured right hand, in which the injured hand was the nondominant hand in most of the patients. The reason behind the frequent injury to non-dominant limb has not been clearly explained by the literature but it may be due to tendency of children to protect the dominant hand while falling. Mechanism of injury in this study was predominantly fall from height 82 $(71.92 \%)$ fallowed by sports injury $28(24.56 \%)$ and Road traffic accident 4 (3.50\%). Similar study was performed by Khan KS3 which showed that the mechanism of injury was a fall while running in 87 (74.3\%), fall from a height in $16(13.7 \%)$, fall of a bicycle in $8(6.8 \%)$ and $6(5.1 \%)$ were miscellaneous. Most of the patients $78(68.42 \%)$ presented to the hospital after $12 \mathrm{hrs}$ of injury, this may attributed to the mild form of injury, less pain, mild tenderness, less swelling and no restriction of activities11-15.

There was a significant decrease in the cost of bandage application in soft bandage group compared to $\mathrm{B} \backslash \mathrm{E}$ cast group. In this study average cost of soft bandage application was Rs.301.25 compared to average minimal cost of one $\mathrm{B} \backslash \mathrm{E}$ cast application of Rs. 541.92. Thus, even by the nominal charge of bandage or cast application in a government institution, there is a significant reduction in the cost of soft bandage application as compared to below-elbow cast. These findings are comparable with the study done by Davidson J.S 1 which showed marked difference between the costs of treatment of buckle fracture by soft cast compared with hard rigid plaster cast. In our study, patients treated with soft bandage had mean dorsiflexion of $69.36^{\circ}$ at 4 weeks after removal of bandage compared to the mean dorsiflexion of wrist in $\mathrm{B} \backslash \mathrm{E}$ cast group which was $64.07^{\circ}$ after cast removal. There was a statistically significant difference between the two groups treated by soft bandage and $B \backslash E$ cast. $(p=0.00)$. Similarly mean palmar flexion of wrist at 4 wks after removal of bandage in soft bandage group was $78.36^{\circ}$ while in $\mathrm{B} \backslash \mathrm{E}$ cast group it was $69.48^{\circ}$ after cast removal. This was also statistically significant. $(p=0.00)$. In soft bandage group, the mean supination of wrist after removal of bandage at 4 wks was $78.50^{\circ}$ compared to the mean supination of wrist in $\mathrm{B} \backslash \mathrm{E}$ cast group which was $73.66^{\circ}$. This was statistically significant $(p=0.00)$. Similarly mean pronation of wrist at 4 wks after removal of bandage in soft bandage group was $68.50^{\circ}$ while in $\mathrm{B} \backslash \mathrm{E}$ cast it was $64.17^{\circ}$. This was also statistically significant. $(p=$ 0.00 ). Symons $\mathrm{S}$ et al. did a study which was 
similar to our study. They found that there were differences in the ROMs of wrist joints after the torus fracture of distal radius was treated with cast and slab in terms of dorsiflexion, palmar flexion, supination, and pronation. This was the important parameter in their study to say that slab is superior to cast to treat distal radius torus fracture. They found the statistically significant result5. In this study both the children and parents were specifically asked if they had lost their school or office days. Children who belonged to soft bandage group lost their school for mean of 1.6 days whereas those belonging to $\mathrm{B} \backslash \mathrm{E}$ cast group lost for 2.8 days. Parents in both the group also lost their office days for 1 to 3 days. The loss of school days is similar to the study of Khan KS et al. in which average loss of school days were 1.2 and 2.1 days respectively3.

In this study, patients and their parents at last follow up i.e. 4 weeks were subjected to a set of questions. The questionnaire asked about treatment received either in bandage or plaster cast using a series of semantic scales from which we were able to grade each patient's response. The parents' responses to the questionnaire were analyzed. Questions were asked with regard to comfort of each treatment, pain experienced, movement of the affected wrist, removal of the bandage or cast, convenience of each treatment, parental concern over entering the trial, and the information sheets themselves. Patients were asked how comfortable they found treatment in either the soft bandage or the $\mathrm{B} \backslash \mathrm{E}$ plaster cast. Twenty eight $(49.12 \%)$ patients in the soft bandage group were very comfortable, $26(45.61 \%)$ were comfortable and 3 patient $(5.26 \%)$ was undecided and neither of the patients was uncomfortable. Whereas in the $\mathrm{B} \backslash \mathrm{E}$ cast group, neither of the patients was very comfortable but 28 $(49.12 \%)$ patients were comfortable, 17 (29.86\%) patients were undecided and $12(21.05 \%)$ patients were uncomfortable. Patients were asked about pain in either the soft bandage group or the $\mathrm{B} \backslash \mathrm{E}$ plaster cast. For those treated in a soft bandage group 15.78 $\%$ (9) had pain and $84.21 \%$ (48) did not have pain in a bandage. For those treated in a $\mathrm{B} \backslash \mathrm{E}$ plaster cast, $38.59 \%$ (22) had pain and $61.40 \%$ (35) did not have pain in a plaster cast. All patients were asked about the duration of the pain they experienced. For patients who had pain in the bandage, most of them had pain for 2 days. For those who had pain in the plaster cast, most of them had pain for 4 to 5 days. Patients were asked whether they had moved their wrist in the bandage. Fourty $(70.17 \%)$ patients in the soft bandage group agreed that they used and moved their wrist and $17(29.82 \%)$ patients didn't. No patients treated in the $\mathrm{B} \backslash \mathrm{E}$ plaster cast removed their cast or were able to move their wrist until the fourth week, upon removal. Patients treated in a soft bandage group were asked whether they removed the bandage during treatment. Twentyeight $(49.12 \%)$ patients said that they removed the bandage and re-applied at home while in treatment whereas $29(50.87 \%)$ patients did not remove. It was not possible to remove cast in $\mathrm{B} \backslash \mathrm{E}$ group. Patients were asked whether they found treatment in either the bandage or the plaster cast convenient. Patients were asked whether they found treatment in either the bandage or the plaster cast convenient. In soft bandage group, 52 (91.22\%) patients were convenient regarding the form of treatment and 5 $(8.77 \%)$ were not whereas $36(63.15 \%)$ patients were convenient and 21(36.84\%) patients were not convenient in $\mathrm{B} \backslash \mathrm{E}$ cast group. Parents were asked whether they felt worried entering the trial. In soft bandage group, $52(91.22 \%)$ parents were convenient regarding the form of treatment and 5 $(8.77 \%)$ were not whereas $36(63.15 \%)$ patients were convenient and 21(36.84\%) patients were not convenient in $\mathrm{B} \backslash \mathrm{E}$ cast group. 2, 16-20

This study is based on the original study done by West $\mathrm{S}$ et al 2 who also compared the soft bandage with $\mathrm{B} \backslash \mathrm{E}$ cast for the treatment of isolated distal radius torus fracture. The results obtained by this work are nearly similar to that of original study and are statistically significant. The main problem we encountered in the execution of this trial was recruitment. Parents were happier to accept what was considered the "normal" treatment of a fracture in the form of a plaster cast. When confronted with the information sheet and the need for a special consent form, parents were also happier to accept conventional treatment. From our results, buckle fractures of the distal radius are being over treated in anything other than a bandage. The true buckle fracture is a stable injury. This may account for the delayed presentation of such injuries to the accident and emergency department after what has been perceived as a trivial injury by the parent. Many such injuries may go undiagnosed, as children never present to the hospital. With the provision of full, clear, and uncomplicated instructions on the nature of buckle fractures, these injuries can be treated safely in a soft bandage alone, with quicker return of function than with 
plaster cast treatment.

\section{CONCLUSION}

Treatment of distal radius torus fracture with soft bandage is a cost-effective and safe method of immobilization in children below 14 years of age. Torus fractures of the distal radius in children can be safely and conveniently managed with soft bandage only without the need for more than one fracture clinic appointment that can be easily removed by parents at home. Parental satisfaction with such a regimen approaches $100 \%$ and fracture clinic workload is reduced, with no additional costs. This is a single hospital based study so a randomized controlled trial with a large sample size and a longer duration of follow-up is recommended.

\section{REFERENCES}

1. Davidson JS, Brown DJ, Barnes SN, Bruce CE. Simple treatment for torus fracture of the distal radius. $\mathrm{J}$ Bone Joint Surg. 2001;83-B:1173-5. DOI:10.1302/0301620X.83B8.11451.

2. West S, Andrews J, Bebbington A, Ennis O, Alderman P. Buckle fractures of the distal radius are safely treated in a soft bandage: a randomized prospective trial of bandage versus plaster cast. J Paediatr Orthop. 2005;25:322-5. DOI:10.1097/01.bpo.0000152909.16045.38.

3. Khan KS, Grufferty A, Gallagher O, Moore DP, Fogarty $\mathrm{E}$, Dowling F. A randomized trial of 'soft cast' for distal radius buckle fractures in children. Acta Orthop Belg. 2007;73:594-7. PMID:18019914.

4. Solan MC, Rees R, Daly K. Current management of torus fracture of distal radius. Injury. 2002;33:503-5. DOI:10.1016/S0020-1383(01)00198-X.

5. Symons S, Rowsell M, Bhowal B, Dias JJ. Hospital vs home management of children with buckle fracture of the distal radius. J Bone Joint Surg. 2001;83-B:556-60. DOI:10.1302/0301-620X.83B4.11211.

6. Plint AC, Perry JJ, Correll R, Gaboury I, Lawton L. A randomized, controlled trial of removable splinting versus casting for wrist buckle fractures in children. Pediatrics. 2006;117(3):691-7. DOI:10.1542/peds.2005-0801; PMID: 16510648.

7. Van Bosse HJP, Patel RJ, Thacker M, Sala D. Minimalistic approach to treating wrist torus fractures. $\mathrm{J}$ Paediatr Orthop. 2005;25:495-500. DOI:10.1097/01.bpo.0000161098.38716.9b

8. Plint AC, Perry JJ, Tsang JLY. Pediatric wrist buckle fractures: should we just splint and go? Can J Emerg Med. 2004;6:397-401. DOI:10.1017/S1481803500009386.

9. Schranz PJ, Fagg PS. Undisplaced fractures of the distal third of the radius in children: an innocent fracture? Injury. 1992;23:165-7. DOI:10.1016/S0020-1383(05) 80036-1.

10. Farbman KS, Vinci RJ, Cranley WR, Creevy WR, Bauchner $H$. The role of serial radiographies in the management of pediatric torus fractures. Arch Pediatr Adolesc Med. 1999;153:923-5. DOI:10.1001/ archpedi.153.9.923; PMID:10482206.

11. Kennedy SA, Slobogean GP, Mulpuri K. Does degree of immobilization influence refracture rate in the forearm buckle fracture? J Pediatr Orthop B. 2010;19(1):77-81. DOI:10.1097/BPB.0b013e32832f067a; PMID:19738494.
12. Plint A, Clifford T, Perry J, Bulloch B, Pusic M, Lalani A, et al. Wrist buckle fractures: a survey of current practice patterns and attitudes towards immobilization. Can J Emerg Med. 2003;5(2):95-100. PMID:17475098.

13. Powell CV, Kelly AM, Williams A. Determining the minimum clinically significant difference in visual analog pain score for children. Ann Emerg Med. 2001;37:28-31. DOI:10.1067/mem.2001.111517; PMID:11145767.

14. Hernandez JA, Swischuk LE, Yngve DA, Carmichael KD. The angled buckle fracture in pediatrics: a frequently missed fracture. Emergency Radiology. 2003;10(2):71-5. DOI:10.1007/s10140-003-0288-1; PMID:15290510.

15. Plint A, Perry JJ, Tsang JYL. Pediatric wrist buckle fractures: management and outcomes. Can J Emerg Med. 2004;6:397-401.

16. Armstrong PF, Joughlin VE, Clarke HM. Pediatric fractures of the forearm, wrist, and hand. In: Green NE, Swiontkowski MF, eds. Skeletal Trauma in Children. Philadelphia, PA: WB Saunders; 1998.p.157.

17. Bruce ASW, Flowers M, Burke D, Sprigg A. Radial forearm buckle fractures, an audit of patient and parent satisfaction with treatment in an alder hey splint instead of plaster. [Abstract]. J Bone Joint Surg Br. 2003; 85B (Supp I): 28 .

18. Oakley EA, Ooi KS, Barnett PLJ. A Randomized controlled trial of 2 methods of immobilizing torus fractures of the distal forearm. Pediatr Emerg Care. 2008;24:65-70. DOI:10.1097/PEC.0b013e318163db13; PMID:18277840.

19. Randsborg PH, Sivertsen EA. Distal radius fractures in children: substantial difference in stability between buckle and greenstick fractures. Acta Orthopaedica. 2009;80 (5):585-9. DOI: $10.3109 / 17453670903316850$; PMID:19916694; PMCID:PMC2823323.

20. Pountos I, Clegg J, Siddiqui A. Diagnosis and treatment of greenstick and torus fractures of the distal radius in children: a prospective randomized single blind study. J Child Orthop. 2010;4(4):321-6. DOI:10.1007/s1 1832-0100269-3; PMID:21804894; PMCID:PMC2908342.

21. Firmin F, Crouch R. Splinting versus casting of "torus" fractures to the distal radius in the pediatric patient presenting at the emergency department (ED): a literature review. International Emergency Nursing. 2009;17(3):173 -8. DOI:10.1016/j.ienj.2009.03.006; PMID:19577205.

22. Boutis K, Willan A, Babyn P, Goeree R, Howard A. Cast versus splint in children with minimally angulated fractures of the distal radius: a randomized controlled trial. CMAJ. 2010;182(14):1507-12. DOI:10.1503/ cmaj.100119; PMID:20823169; PMCID:PMC2950182. 